\title{
Pedagogical Approaches and Techniques of Non- Education Graduates Teaching General Mathematics in the Senior High School
}

\author{
Cherry Rose T. Malgapo ${ }^{1}$, Cristo Mark D. Ancheta ${ }^{2}$
}

\author{
${ }^{1}$ Mathematics Teacher, Aliaga National High School, Nueva Ecija, Philippines \\ ${ }^{2}$ Mathematics Professor, Nueva Ecija University of Science and Technology, Nueva Ecija, Philippines
}

Received: 10 Oct 2020; Received in revised form: 09 Nov 2020; Accepted: 11 Nov 2020; Available online: 16 Nov 2020 (C)2020 The Author(s). Published by Infogain Publication. This is an open access article under the CC BY license (https://creativecommons.org/licenses/by/4.0/).

\begin{abstract}
Pedagogical approaches and techniques are common among teachers, but some are more effective and appropriate than others. The study is focused on identifying the basic pedagogical approaches and techniques of Senior High School non-education graduate teachers (SHSNEGT) teaching General Mathematics using the purposive sampling method, the main respondents of the study are 12 SHSNEGT and two experts per school in Aliaga District, Municipality of Aliaga in Nueva Ecija. With the use of concurrent mixed-method research design and data statistical analysis, the results show that teacher-respondents whose age ranges from 25 to 38 are categorized as "young adults and professionals" and 83.33\% are female with two years teaching experience in SHS, having BS Degree and specialization related in business courses as well as in their previous work. Using logical/matrix and inductive analysis and weighted mean, the subject matter-centered approach has weighted mean3.92 and the teacher-centered approach has 3.31 mean and considered dominant and "significantly evident" in teaching General Mathematics. With regards to pedagogical techniques applied by the teachers using weighted mean, "setting of objectives" has the highest weighted mean of 3.44, lesson development has 3.39, application 3.36, evaluation 3.35 and materials being used have 3.28. All items with a verbal description of "outstanding". They set their objectives based on learning competencies with three domains of learning, using board, with motivational activity on lesson development and board-work, group activity, problem sets, and quiz as a means of evaluation. Using ANOVA test analysis, previous work has significant differences in the pedagogical approaches $(F=10.667$, sig $=.004)$ but there are no significant differences in terms of techniques $(F=.510$, sig=.65). The majority of the teachers are challenged about the attitude and behavior of the students towards learning. To develop productive notions of teaching, teachers must think of appropriate pedagogical approaches and techniques for every topic/lesson.
\end{abstract}

Keywords- General Mathematics, Non-Education Graduate Teachers, Outstanding, Pedagogical Approach, and Techniques, Senior High School.

\section{INTRODUCTION}

Pedagogical approaches are common among teachers, but some are more effective and appropriate than others. Effective approaches often depend on particular subject matter to be taught and on understanding the diverse needs of different learners.[1] Teachers' approaches differ in the level of the student's participation and teachers' teaching techniques are a series of related and progressive acts performed to achieve the objectives of the lesson. An approach gives rise to methods, the way teachers teach by utilizing classroom activities or techniques that educationally help learners. 
The pedagogical approach is like a description of how educators ponder about teaching the students. It is a set of principles, beliefs, or ideas about the nature of learning which is applied in the classroom.[2] Teachers always sustain the interest of learners through the use of encouraging questions, set formative assessments, and providing constructive feedback to notice and measure students' improvement. In other words, the teaching approach is the teacher's own personal philosophy of teaching. (Principle of Teaching: Different Methods and Approaches) [3].

There are different approaches that teachers integrate with their teaching and learning process like teacher-centered, learner-centered, subject-matter centered, teacher dominated, interactive, constructivist, collaborative, direct, indirect, individualistic, research base approach and integrated approach, meta-cognitive approach, and problembased approach. Some teachers usually use only one teaching approach, but some use a combination of two or more approaches. [4]All these teaching approaches need to have appropriate teaching techniques that the teachers can use to achieve learning goals and objectives.

Effective teaching strategies and approaches, classroom management, and mastery of the subjects are the main focus for the holistic development of the learners. [5]Teachers must recognize individual differences among students and adjust instruction appropriate for them. Educators play varied and vital roles in the classroom and considered as light by the students. As teachers, they are entrusted with so many responsibilities that range from the very simple to most complex and very challenging jobs. They need to understand that they should be motivated in doing their work, so as to have motivated learners in the classroom.

Teachers must recognize the diversity and complexity of the situation in the classroom including the ethnicity, gender, culture, language abilities, and interests of students. Getting students to work and learn in class is largely influenced by all these factors. [6]Classroom diversity exists not only among students but may also be exacerbated by language and cultural differences between teachers and students.

According to Beausaert (2013), the teachers, being the focal figure in education, must be competent and knowledgeable to impart the knowledge they could give to their students. Good teaching is not only a professional matter but also a personal one. [7]
Based on the preceding arguments, it showed that a class would not be a class if the teacher had failed to motivate the learners; there opens the gate of the approaches and techniques the teacher uses to encourage the class to not just learn, but also to absorb every information and ideas then consider those as additional knowledge.

According to the article "Understanding differences in teaching approaches in Higher Education: An Evidence-Based Perspective", published in 2014, the teaching approach refers to the set of principles, beliefs, or ideas about the nature of learning which is applied to the classroom. Teaching technique is a long-term plan of action designed to achieve a particular goal - that is to impart knowledge to the learners that will not only stay at the moment but will be nurtured and instilled in their minds; to create critical thinking individuals and to produce life-long learning skills.[8]

[9]The pedagogical approach has a lot of divisions that suit the needs of both the learners and the teachers. Teaching techniques depend upon the discretion of the teachers themselves on how they are going to apply those approaches and techniques in terms of objective settings, materials to be used, lesson development, application, and evaluation in the sets of lessons. [10]

The Philippine educational system is now in the $7^{\text {th }}$ year of implementation of K-12 curriculum however Senior High School is only in its $3^{\text {rd }}$ year of implementation, for the advancement in Basic Education legalized by the Republic Act 10533 or the Enhance Basic Education Act of 2013. This law implements the K-12 Program which covers one (1) year in kindergarten, six (6) years in elementary, and six (6) years in secondary education which has four (4) years of junior high school and two (2) years of senior high school education.

Senior High School Teacher refers to a person who meets the minimum requirements whether on a full-time or part-time basis and qualified to practice teaching profession under RA 7836 and/or those performing functions in support of education such as standard-setting, policy, and programs formulation, research, and sector monitoring and evaluation.

Despite the number of years of implementation of the K-12 curriculum the Department of Education continuously hires professionals that most of them noneducation graduates because of the demand needs of teachers and their expertise in line with the Senior High 
School curriculum that needs to cater to the different tracks/strands offerings. They believe that non-education graduates who previously worked from other industries and business establishments can satisfy the needs in a teaching position.[11]Non-education graduates are accepted to teach in senior high school as long as they meet all the necessary requirements, have successfully undergone the application process for a SHS teaching position, and as long as they come from industries and have fields of specialization like business managers, engineers, nurses, architects, etc. Most of them are given mathematics as teaching loads particularly General Mathematics.

General Mathematics is one of the core subjects in the senior high school curriculum wherein most of the teachers handling this subject are non-education graduates. They are hired because schools are in dire need of teachers.[12]

The researcher decided to conduct this study to determine and identify the basic pedagogical approaches and techniques applied by Senior High School NonEducation Graduate Teachers in teaching General Mathematics with techniques and approaches like teachercentered, student-center, subject matter-centered, interactive, integrated meta-cognitive, constructivist, problem-based approach.[13] Teachers set their lesson objectives, materials to be used, lesson development, application, and evaluation in selected lessons or topics in general mathematics like simple and compound interest; annuities, propositions and its operations, truth values, and tautology.

It is with huge hope that this research study can generate significant results.

\section{THEORETICAL/CONCEPTUAL FRAMEWORK}

The research study was based on several theories and references that exhibit the vital effects of teaching approaches and techniques toward the learning process of the students in General Mathematics.

This study was anchored on pedagogical theory. Pedagogy is the study of the theory and practice of education. This theory was based on the learning theory of Watson in the early $20^{\text {th }}$ century. It is concerned with the underlying values and principles that influence our approaches to learning, teaching, and assessment. It is thus important to think about how we teach, how we deliver the information to our students that must be delivered. The National College for Teaching and Leadership's paper (2012), nine characteristics of highly successful pedagogies based on their review of the literature. They conclude that effective pedagogies: (1.) give serious consideration to pupil's voice; (2.) depend on behavior (what teachers do), knowledge and understanding (what teachers know) and beliefs (why teachers act as they do); (3.) involve clear thinking about longer-term learning outcomes as well as short-term goals; (4.) build on pupils' prior learning and experience; (5.) involve scaffolding pupil learning; (6.) involve a range of techniques, including whole-class and structured group work, guided learning and individual activity; (7.) focus on developing higher-order thinking and meta-cognition, and make good use of dialogue and questioning in order to do so ; (8.) embed assessment for learning; and (9.) are inclusive and take the diverse needs of a range of learners, as well as matters of student equity, into account.

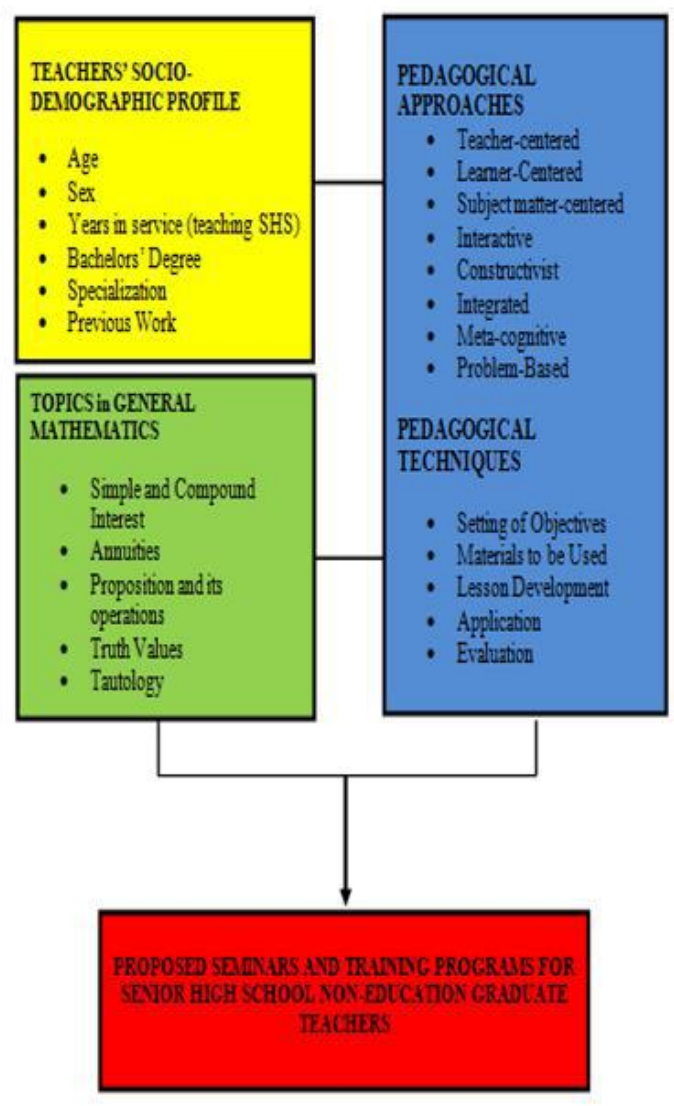

Fig.1: The research Paradigm 
And with regards to the concepts of this study, it was based on autonomy concepts of Michael Moore, all teaching-learning process has three components: first, preparation activities, in which objectives and strategies are set; second, application activities, in which information, datum, and ideas are actualized and lastly, evaluation activities, in which a judgment is made on the efficiency of reaching the objectives of teaching processes.

The researcher also modified three to five components anchored on the DepEd Nueva Ecija components in the daily lesson log (DLL) wherein the five components were shown and integrated as teaching approaches and techniques. These are setting of objectives wherein all the objectives are set in three domains of learning, materials to be used lesson development in which pedagogical techniques are applied for the particular topic and application in which pedagogical approaches applied on are known and evaluated.

The preceding statements are products of the various theories where the study was anchored and the researcher's view of the problem being studied.

The above-cited concept guided this study in the teaching approaches and techniques of Senior High School NonEducation Graduate Teachers (SHSNEGT) in teaching general mathematics based on selected lessons/topics listed as least learned in item analysis in previous years. These are simple interest, compound interest, annuities, truth values, and tautology.

The researcher used the IV-DV model or independent variable and dependent variable. The independent variables are teachers' socio-demographic profile in terms of age, sex, years in teaching services, bachelors' degree, specialization, and previous work, and the selected least learned topics in Gen. Mathematics would also be included.

The dependent variables are the pedagogical approaches (teacher-centered, learner-centered, subjectmatter centered, interactive, integrated, meta-cognitive, constructivist, and problem-based) and techniques in terms of objectives settings, materials being used, lesson development, application and evaluation of teachers in teaching General Mathematics.

The output of the study was the proposed seminars and training programs for Senior High School NonEducation Graduates teachers.

\section{OBJECTIVES OF THE STUDY}

This paper sought to answer the following:

1. What is the socio-demographic profile of teacherrespondents teaching General Mathematics in terms of age, sex, years in service (teaching SHS), bachelor's degree, specialization, and previous work?

2. What are the pedagogical approaches applied by the teacher-respondents in general mathematics lessons: simple interest, compound interest, annuities, truth values, and tautology?

3. How do the pedagogical techniques of teacherrespondents be described in terms of setting of objectives, materials to be used, lesson development, application, and evaluation?

4. How may the pedagogical approaches and techniques applied by the teacher-respondents in teaching selected topics in General Mathematics be compared?

5. Are there significant differences in pedagogical approaches and techniques applied in General Mathematics based on teachers' profiles?

\section{METHODOLOGY}

This study utilized a mixed-method research design, a combination of the qualitative and quantitative design in order to secure a relevant answer to the problem of the study. And in selecting the sample respondents, the researcher used a purposive sampling technique, a total of 12 SHS teachers, 6 school heads, and 6 master teachers were selected as respondents coming from public secondary schools in Congressional District 1, Division of Nueva Ecija.A survey questionnaire, observation tool, and interview questions served as the instrument to gather the needed data and were personally designed, developed, and validated by the researchers. The questionnaire was accompanied by a letter stating the purpose of the survey and personally administered by the researchers. The respondents were briefed on the significance of the survey questions so that the researcher would elicit honest responses from them. And finally, the data gathered will be tabulated and analyzed thru data and statistical tools analysis. 


\section{RESULTS AND DISCUSSION}

\section{Socio-Demographic Profile of Teachers}

In terms of age, there are two teacher-respondents from each of these ages: $28,34,36,38$, and there is only one teacher for each of the following age range 25, 29, 31, and 32. They are all categorized as "young professionals" or " young adults".As to sex, $10(83.33 \%)$ of the teachers are female and $2(16.67 \%)$ are male.With regards to years in service (teaching SHS), five of the teachers have two years with the verbal description "experienced", four of the teachers have three years with verbal description "highly experienced" and three of the teachers have one-year teaching experience considered as "least experienced".On a bachelor's degree, five teachers have a BS Degree related to business degree courses like management, entrepreneurship, marketing, and accounting. Two of the teachers have a BS Degree in the field of Engineering, Computer courses, and in other fields of studies (BS Nursing and $A B$ MassCom).As to specialization, six of the teachers are specialized in business-related industries, two in Mathematics, another two in computer-related works and the remaining two specialized in other fields (computerrelated, auditor, none, etc.).Six teachers have previous work in sales/clerical work-related, two teachers are engineers, another two are teachers, and the remaining two previously worked as journalists.

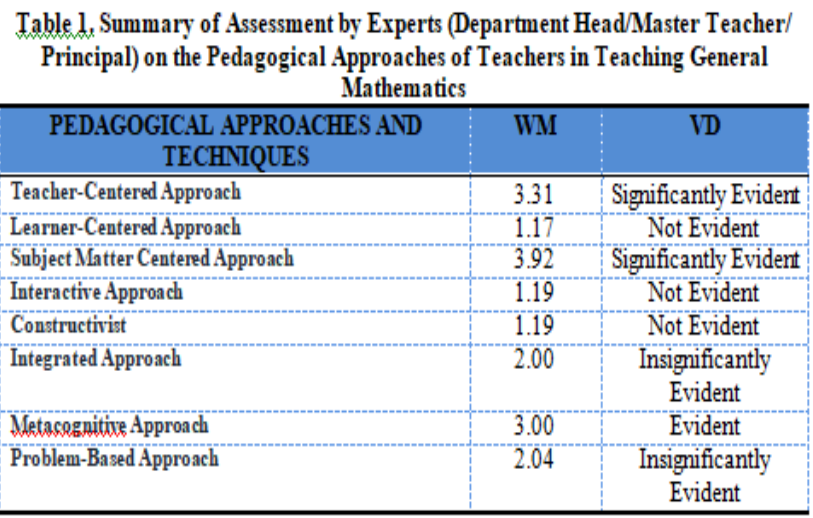

\section{Pedagogical Approaches and Techniques}

Table 1, shows the summary of assessments by experts (Department Head/Master Teacher/ Principal) and from the series of observations on pedagogical approaches of the teachers teaching General Mathematics, the subject matter-centered approach has a weighted mean of 3.92 with a verbal description of "significantly evident". This is followed by a teacher-centered approach with a weighted mean of 3.31 and with a verbal interpretation of " significantly evident", meta-cognitive approach 3.00 with the verbal description "evident" and problem-based approach 2.04 interpreted as "evident".

Table 2. Summary of Pedagogical Techniques Applied by SHSNEGT in Teaching
General Inathematics
\begin{tabular}{|l|c|c|}
\hline Pedagogical Approaches and Techniques & WMI & Verbal Description \\
\hline Settingof Objectives & 3.44 & Outstanding \\
\hline Matenalisbeingused & 3.28 & Outstanding \\
\hline Lesson Development & 3.39 & Outstanding \\
\hline Application & 3.36 & Outstanding \\
\hline Evaluation & 3.35 & Outstanding \\
\hline
\end{tabular}

On validation of data gathered through series of actual observations, the teachers use varied pedagogical approaches and techniques in different topics/lessons like simple interest, compound interest, and annuities, subject matter-centered approach, problem-based approach, teacher-centered approach are evident. The techniques used are motivational activities, board-work, and group activities. And in topics truth values and tautology, teacher-centered and subject matter-centered with lecture/discussion is evident.

And the results of the interview, the majority of them are preparing their lesson objectives ahead of time using various references and they consider the individual differences of the students in selecting their resources. They say that the problem-based approach, collaboration, and group learning techniques are the most helpful and effective to apply in General Mathematics.

\section{Pedagogical approaches and techniques applied by SHSNEGT teaching General Mathematics}

Table 2 presented the pedagogical approaches and techniques applied by teachers teaching General Mathematics, "setting of objectives" has the highest weighted mean, 3.44 with the verbal interpretation of "outstanding". This is followed by lesson development with a mean of 3.39, application with 3.36, evaluation with 3.35 , and materials being used with 3.28 and all having a verbal interpretation of "outstanding".

4. Comparison in pedagogical approaches and techniques applied by SHSNEGT teaching General Mathematics 
The teachers execute and evidently show different approaches and techniques like subject matter-center, teacher-centered, and problem-based approaches in simple interest, compound interest, and annuities, while in truth values and tautology are lecture/discussion techniques, therefore there are no differences in the pedagogical approaches and techniques applied by the teachers in topics/lessons in General Mathematics. They execute different approaches in the first three topics maybe because the topics are more on formulas while the two topics about truth values and tautology are requiring logical analysis of statement and the teachers had no enough knowledge of them since the expertise of the majority of teachers are not aligned in that field of specialization.

\section{Differences in pedagogical approaches and techniques applied in teaching and based on teachers' profile}

Table 3, shows the differences in pedagogical approaches previous work has an F-value of 10.667 and sig. of .004 , reveals that there is a significant difference in pedagogical approaches but has no difference in techniques (F-value of 0.571 and sig. .650). Pedagogical approaches and techniques applied in General Mathematics have no significant differences in terms of teachers' age, sex, years in service, bachelor's degree, and specialization.

Table 3. Differences in Pedagogical Approaches and Techniques Applied in

\begin{tabular}{|c|c|c|c|c|c|c|}
\hline & \multirow{2}{*}{\multicolumn{3}{|c|}{ TECHNIQUES }} \\
\hline \multirow{2}{*}{ PROFILE } & & & & & & \\
\hline & $\mathrm{F}$ & sig & $\begin{array}{c}\text { Verbal } \\
\text { Interpretation }\end{array}$ & $\mathrm{F}$ & Sig & $\begin{array}{c}\text { Verbal } \\
\text { Interpretation }\end{array}$ \\
\hline AGE & 2.857 & .164 & $\mathrm{NS}$ & 2.984 & .154 & NS \\
\hline SEX & 0.465 & .511 & NS & 1.053 & .329 & NS \\
\hline YEARS IN SERVICE & 1.215 & 341 & NS & 0.115 & .892 & NS \\
\hline $\begin{array}{l}\text { BACHELOR'S } \\
\text { DEGREE }\end{array}$ & 3.435 & .072 & NS & .261 & .851 & NS \\
\hline SPECIALIZATION & 0.333 & .802 & $\mathrm{NS}$ & 0.615 & .624 & $\mathrm{NS}$ \\
\hline PREVIOUS WORK & 10.667 & 0.004 & $\mathrm{~s}$ & 0.571 & .650 & $\mathrm{NS}$ \\
\hline
\end{tabular}

\section{CONCLUSION}

Based on the findings the following conclusions are attained.

1. The SHSNEGT are considered as young professionals and the majority of them are female with entry-level in Senior High School, having BS degree and specialization with previous work related to business courses and industry, therefore, SHSNEGT is eager to learn. They can easily adopt different environment settings especially in teaching General Mathematics as they can apply their expertise and skills gained from their previous experiences and prior knowledge related to the topics.

2. There can be no doubt that teacher-centered, subject-matter centered and problem-based pedagogical approaches are dominant in teachers and collaborative, group work activity and boardwork in techniques are also evident in teaching General Mathematics. The teachers use two to three pedagogical approaches among several approaches in teaching.

3. On pedagogical techniques applied in General Mathematics, the setting of objectives has the highest weighted mean 3.44 interpreted as "outstanding", it is concluded that teachers planned well with the integration of three domains of learning - cognitive, psychomotor, and affective to satisfy the learning competencies and objectives of the topic/lesson.

4. There are no differences in the pedagogical approaches and techniques applied by teachers, therefore the teachers have the same pedagogical approaches and techniques applied in teaching General Mathematics. Because the topic is new to them, they can only rely on what they know and the easiest way to deliver the subject matter.

5. The teachers' previous has there is a significant difference in pedagogical approaches but had no significant difference in pedagogical technique, therefore teachers' capability, knowledge, and skills gained from their previous work have a great impact to pedagogical approaches that can be applied in teaching with diverse learners and different situations. On the other hand, previous has no significant difference in pedagogical techniques because teaching is different from their previous environment, so all teachers used the basic techniques in teaching General Mathematics.

\section{RECOMMENDATIONS}

Based on the conclusions the following are recommended.

1. Since the teachers are young professionals regardless of the sex they are eager to learn, they can share their ideas, knowledge, and skills with 
others and easily adjust in a different environment it is recommended for them to pursue graduate studies that are aligned to their field of specialization in teaching. They should attend more seminars and trainings on pedagogical approaches and techniques that can be applied for the current work as Senior High School teaching position.

2. The teachers may try to use and integrate other pedagogical approaches and techniquesthat will make teaching and learning [14] more interesting, fun, and enjoyable like interactive approach, inquiry-based approach, constructivist approach, integrated approach, and many more. They may integrate virtual simulation that most of the students confirmed to be more helpful and effective.

3. Since pedagogical techniques applied by teachers have been found outstanding, teachers may continue to look into the other side of other techniques especially in planning and selecting appropriate approaches that best suited to individual differences and needs of the students to satisfy their learning objectives and competencies.

4. Given that no differences in the pedagogical approaches and techniques applied in teaching General Mathematics [15] and the topic is new for the teachers, it is recommended for school heads or department heads to form a group for mentoring and coaching teachers in different teaching and learning tasks to improve teachers' pedagogical approaches and techniques that will maximize learning time and activities.

5. Previous work is found out with significant differences in pedagogical approaches. It is recommended that the good side of it may serve as their springboard for continuous professional growth and development in the selection, preparation, and utilization of instructional materials in General Mathematics.

6. Teachers may consider students' individual differences, implementing classroom rules and regulations and they should integrate more patience in teaching whereas school heads showed to provide the budget for instructional materials needed in teaching General Mathematics.
7. Based on the conclusion of this study, it is recommended to have continuous development, organization, and implementation seminars and training programs for improvement and enhancement of teachers' pedagogical approaches and techniques in teaching different learning areas.

\section{ACKNOWLEDGEMENT}

With God as the main source of abundant blessings, the researchers wish to express their heartfelt gratitude and appreciation to those who are in one way or another contributed to the completion of the study.

\section{REFERENCES}

[1] Adunola, O. (2011),“The Impact of Teachers' Teaching Methods on the Academic Performance of Primary School Pupils in Ijebu-Ode Local cut Area of Ogun State," Ego Booster Books, Ogun State, Nigeria.

[2] Beausaert, S. (2013). Effects of using a personal development plan on learning and development. Journal of Workplace Learning. ISSN 1366-5626

[3] Cristillo, L. (2010). Teacher-Centered Dominated Approaches. Academic Journal of Educational Research. 2016

[4] Das (2010). The Internship of Teaching. Handbook Department of Education. General Mathematics. Teachers' Guide and Learner's Materials

[5] Educational Consultancy and Research Center, (2012), Educational Sciences: Theory and Practice-12 (1). Winter. 497-505

Hill-Miller, P. (2011). A different approach, different results: A study of mastery learning instruction in a developmental reading class at an urban community college. The University of North Carolina at Charlotte). ProQuest Dissertations and Theses, 120 . Retrieved from: http://search.proquest.com/docview/897948393?accountid=2 8682. (897948393).

[7] Jadama L.M. (2014). Impact of Subject Matter Knowledge of a Teacher in Teaching and Learning Process. School of Education University of The Gambia, Middle Eastern \& African Journal of Educational Research, Issue 7 the Year 2014 20E-mail: ljadama@hotmail.com Mobile: 00220 3650114

[8] Jalbani, L.N. (2014). The Impact of Effective Teaching Strategies on the Students' Academic Performance and Learning Outcomes. ISBN 9783656963530 
[9] J Adv Med Educ Prof. (2016), Effective Teaching Methods in Higher Education: Requirements and Barriers, October 2016;4(4): 170-178. PMCID: PMC5065908, PMID: 27795967

[10] National Research Council, (2013). Improving the health, safety, and well-being of young adults. Institute of Medicine; National Research Council. Washington DC.

[11] Rothstein, J. (2010). Teacher quality in educational production: Tracking, decay, and student achievement. Quarterly Journal of Economics, 125(1), 175-214.

[12] Rice J. K., (2010). The impact of teacher experience, Examining The Evidence and Policy Implication. National Center for Analysis of Longitudinal Data in Education Research.

[13] Subia, G. S. (2020). Treasure Chess: Worthy Contributions of the Game in the Lives of Student Champions. The Normal Lights, 14(1),100-121.

[14] Subia, G., Marcos, M., Valdez, A., Pascual, L. \& Liangco, M. (2020). Cognitive Levels as Measure of Higher Order Thinking Skills in Senior High School Mathematics of Science,Technology, Engineering, and Mathematics (STEM)Graduates. Technology Reports of Kansai University. Volume62, Issue 3, pp 261-268. 